\section{Cellular Physiology and Biochemistry}

Cell Physiol Biochem 2017;43:1413-1424 DOI: 10.1159/000481873

Published online: October 10, 2017

Accepted: August 23, 2017

This article is licensed under the Creative Commons Attribution-NonCommercial-NoDerivatives 4.0 International License (CC BY-NC-ND) (http://www.karger.com/Services/OpenAccessLicense). Usage and distribution for commercial purposes as well as any distribution of modified material requires written permission.

(C) 2017 The Author(s)

Review

\title{
The Emerging Roles of CIB1 in Cancer
}

\author{
Xianwang Wang ${ }^{a, b, c}$ Xiaochun Peng ${ }^{a}$ Xueqing Zhang ${ }^{b}$ Hanyi Xu ${ }^{a}$ \\ Chengbiao Lu $^{\mathrm{c}}$ Lian Liu ${ }^{\mathrm{a}}$ Jiaxing Song ${ }^{\mathrm{d}}$ Yingjie Zhang ${ }^{\mathrm{e}}$
}

aThe Second Clinical Medical School of Yangtze University \& Jingzhou Central Hospital, Jingzhou, ${ }^{b} K e y$ Laboratory of Oncology, Center for Molecular Medicine, School of Medicine, Yangtze University, Jingzhou 'Key Laboratory of Neuronal Oscillation and Disease, School of Medicine, Yangtze University, Jingzhou, dSchool of Medicine, Shenzhen University, Shenzhen, Guangdong, eCollege of Biology, Hunan University, Changsha, Hunan, China

\section{Key Words}

CIB1 • Calcium • Integrin • Cancer • Tumor progression

\begin{abstract}
Calcium and integrin-binding protein 1 (CIB1) is an EF-hand calcium binding protein, which is involved in many cellular processes, including calcium signaling, cell survival and proliferation, cell migration, cell adhesion and apoptosis. A number of studies have found that CIB1 is ubiquitously expressed and is related to various human diseases, such as cancer, Alzheimer's disease (AD), cardiac hypertrophy and male infertility. The mechanism of CIB1 in human diseases is still not clear, although multiple functions of CIB1 are modulated by interacting with numerous interacting partners. As a calcium binding protein, the roles of CIB1 in calcium signaling by binding calcium or modulating some key modulators, such as calcineurin, integrin, inositol 1,4,5-trisphosphate receptor $\left(I_{3} R\right)$ and taste 1 receptor member 2 (TAS1R2). The tumor promoting mechanisms of CIB1 have been described in different aspects, including promoting tumor cell cycle and proliferation, inhibiting tumor cell apoptosis, and mediating tumor cell migration and angiogenesis. In addition, multiple functions of CIB1, such as neural development, taste or gustation functions, and virus infection are also elucidated. These recent advances have significantly expanded our understanding of the knowledge of CIB1 and highlighted the potential mechanisms of CIB1 in tumor progression.
\end{abstract}

\section{Introduction}

Calcium and integrin-binding protein 1 (CIB1, also known as calmyrin and KIP) is a $22 \mathrm{kD}$ protein, identified originally as a binding partner of platelet integrin cytoplasmic domain alpha-IIb/beta3 $(\alpha \operatorname{Ib} \beta 3$ ) [1], and later found to regulate $\alpha \operatorname{IIb} \beta 3$ activation [2, 3] and down regulate inositol 1, 4,5-trisphosphate receptor $\left(\mathrm{IP}_{3} \mathrm{R}\right)$-dependent calcium $\left(\mathrm{Ca}^{2+}\right)$ release [4]. As a calcium-binding protein, the structural properties of CIB1 are most closely related to calcineurin $\mathrm{B}(\mathrm{CnB})$ (57\% sequence similarity to CIB1) and calmodulin (CaM)

$X$. Wang and $X$. Peng contributed equally to this work.

Xianwang Wang and Yingjie Zhang
Key Laboratory of Oncology, Center for Molecular Medicine, School of Medicine Yangtze University, China and College of Biology, Hunan University, Changsha, (China) E-Mail 275379987@qq.com and21392705@qq.com 
(56\% similarity to CIB1) [1,5]. Similar to these $\mathrm{Ca}^{2+}$ related proteins, as shown in Fig. 1, the human CIB1 contains four helix-loop-helix EF hand motifs, two C-terminal EF hand III and EF hand IV are responsible for $\mathrm{Ca}^{2+}$ and magnesium $\left(\mathrm{Mg}^{2+}\right)$ binding $[1,6-10]$. However, CIB1 was found to bind two $\mathrm{Ca}^{2+}$ ions in a sequential manner with dissociation constants near 1.9 and $0.54 \mu \mathrm{M}$ for sites EF-III and EF-IV, respectively. In contrast, CIB1 bound only one $\mathrm{Mg}^{2+}$ ion strongly to EF-III with dissociation constants about $120 \mu \mathrm{M}$ [11]. Of note, CIB1 is usually found in monomeric form and distributed in both the nucleus and cytoplasm [12], and its subcellular localization might be influenced by association with its interacting partners and/or by $\mathrm{Ca}^{2+} / \mathrm{Mg}^{2+}$ levels. Both $\mathrm{Ca}^{2+}$ and $\mathrm{Mg}^{2+}$ binding induce conformational changes which stabilize the higher structure of CIB1, leading to remarkable increases in the thermal stability of the proteins [11]. Yamniuk et al. identified that low affinity $\mathrm{Ca}^{2+}$ binding events that influence the structures of the N- and C-terminal extensions of CIB1 under high $\mathrm{Ca}^{2+}$ crystallization conditions [10]. Studies suggested that $\mathrm{Mg}^{2+}-\mathrm{CIB} 1$ and $\mathrm{Ca}^{2+}-\mathrm{CIB} 1$ exhibit a more ordered 4-EF-hand structure with smaller hydrodynamic radius than a highly flexible molten globule-like CIB1 (not bound to any metals) [6, 8]. A consensus sequence 5'-MGXXXS/T-3' at the CIB1 $\mathrm{N}$ terminus appears to be crucial for its myristoylation modification and plasma membrane localization $[4,7,13,14]$. The myristoylation at the CIB1 $\mathrm{N}$ terminus might interfere with CIB1 cellular function [13, 15-17]. Stabler et al. showed that a myristoylated CIB1 that preferentially interacts with Presenilin 2 (PS2) [13]. The $\mathrm{Ca}^{2+}$-myristoyl switch function of CIB1, and its ability to facilitate agonist-induced plasma membrane localization of SK1, a location where SK1 is known to trigger oncogenic signaling [15]. In addition, CIB1 myristoylation is also important in shuttling $\mathrm{CnB}$ to plasma membrane [16].

A number of studies have further indicated that CIB1 is ubiquitously expressed and is involved in various physiological and pathological processes, including apoptosis [18], cell survival and proliferation [19], cancer [20, 21], cardiovascular diseases [16], and Alzheimer's disease (AD) [22-24]. The precise mechanism between CIB1 and its various binding partners is not clear, although numerous associated proteins of CIB1 have been identified (Table. 1). In this review, we discussed the potential mechanism of CIB1 in $\mathrm{Ca}^{2+}$ signaling and paid more attention to tumor promoting effect of CIB1. Last but not least, some other functions of CIB1 were also involved in this article.

\section{CIB1 and $\mathrm{Ca}^{2+}$ signaling}

In general, intracellular $\mathrm{Ca}^{2+}$ signals result either from its release from the important intracellular stores (such as endoplasmic reticulum (ER) and endo-lysosome), or by activation of $\mathrm{Ca}^{2+}$-conducting channels at the plasma membrane, including voltagedependent $\mathrm{Ca}^{2+}$ channels (VDCCs), $\mathrm{Na}^{+} / \mathrm{Ca}^{2+}$ exchanger (NCX), plasma membrane calciumtransporting ATPases (PMCAs), cyclic nucleotide-gated ion channels (CNGCs), $\alpha$-amino-3hydroxy-5-methyl-4-isoxazolepropionic acid receptor (AMPAR) and N-methyl-D-aspartate

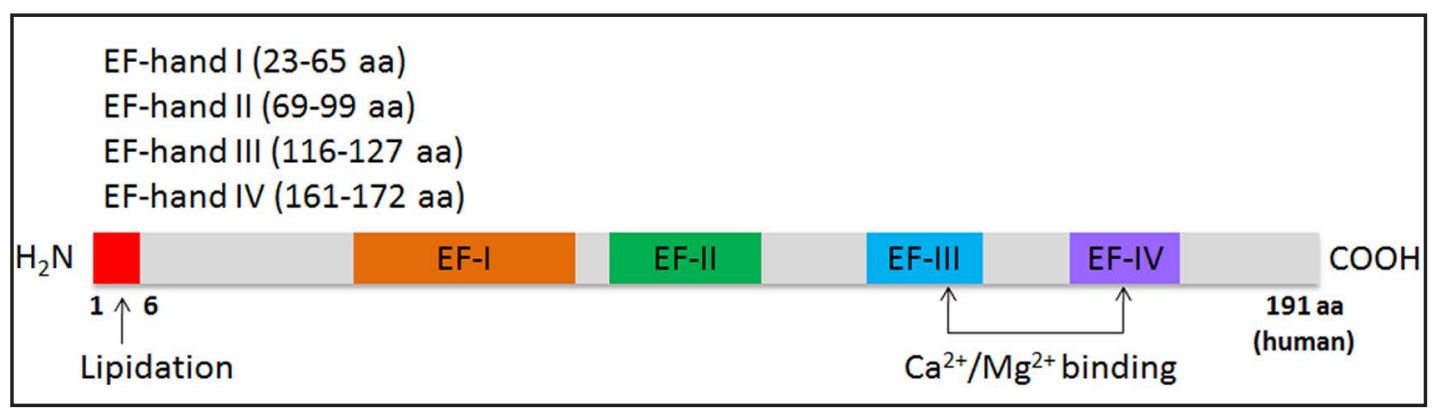

Fig. 1 The basic structure of human CIB1. The CIB1 contains four EF hand motifs, EF-I, EF-II, EF-III and EFIV. The EF-III and IV of CIB1 are essential for $\mathrm{Ca}^{2+} / \mathrm{Mg}^{2+}$ binding. The $\mathrm{N}$-terminus (1-6 aa) of CIB1 is response for its myristoylation modification.

\section{KARGER}




\begin{tabular}{|c|c|}
\hline Cellular Physiology & Cell Physiol Biochem 2017;43:1413-1424 \\
\hline and Biochemistrv & 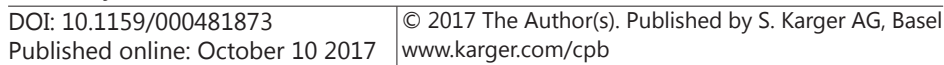 \\
\hline
\end{tabular}

Table. 1 The important interacting partners and potential functions of CIB1.

\begin{tabular}{|c|c|c|}
\hline Partners & Potential functions & References \\
\hline$\alpha \operatorname{IIb} \beta 3$ & platelet aggregation; cell migration; calcium signaling & {$[1,2,61]$} \\
\hline FVIII & platelet aggregation & [24] \\
\hline Rac3 & cell migration & [66] \\
\hline WASP & platelet aggregation; cell migration & [65] \\
\hline FAK/PTK2 & cell migration & {$[64,70]$} \\
\hline PAK1 & cell migration; tumor growth & [67-69] \\
\hline $\mathrm{IP}_{3} \mathrm{R}$ & calcium signaling & {$[4,8,32]$} \\
\hline TAS1R2 & calcium signaling; taste or gustation & [4] \\
\hline Plk2/Snk & cell cycle; cancer progression; DNA damage response; synaptic plasticity & {$[7,39,45]$} \\
\hline Plk3/Fnk & cell cycle; cancer progression; DNA damage response; synaptic plasticity & {$[20,39,44,46]$} \\
\hline PKD2 & tumorigenesis & [46] \\
\hline SK1 & cell proliferation; antiapoptosis; tumor growth & {$[15,17,49]$} \\
\hline ASK1 & antiapoptosis; calcium signaling; & {$[7,57]$} \\
\hline IFI6/G1P3 & cell survival; antiapoptosis & [18] \\
\hline UBR5/EDD & DNA damage response; tumorigenesis & [56] \\
\hline DNA-PKcs/TRF2 & DNA damage response & {$[53,54,56]$} \\
\hline hTERT & telomere homeostasis; cancer cell proliferation & {$[53,54]$} \\
\hline SCG10/stathmin2 & brain development & [72] \\
\hline NBR1/BRCA1/ FEZ1 & neural and brain development & [73] \\
\hline PAX3 & neurogenesis and myogenic differentiation & [75] \\
\hline PS $1 / 2$ & apoptosis; AD & {$[13,14,22,23]$} \\
\hline EphrinA2 & virus infection & [78] \\
\hline $\mathrm{Cn} / \mathrm{CnB}$ & calcium signaling; cardiac hypertrophy; valvular heart disease & {$[16,25,30,79]$} \\
\hline
\end{tabular}

receptor (NMDAR) etc [4, 25-29]. Release of intracellular $\mathrm{Ca}^{2+}$ from ER store through $\mathrm{IP}_{3} \mathrm{R}$ and/or ryanodine receptors (RyR) [25]. Endo-lysosomal $\mathrm{Ca}^{2+}$ stores, on the other hand, are mobilized by two-pore channels (TPCs) and transient receptor potential mucolipin-1 (TRPML1) [25-27].

The CIB1 belong to calcium-binding protein family, and serve important roles in $\mathrm{Ca}^{2+}$ signaling pathways by binding to $\mathrm{Ca}^{2+}$ and some key modulators. For example, CIB1 can interact with $\mathrm{CnB}$ and strongly enhances $\mathrm{CnB}$ membrane localization and activation $[16,30]$. Calcineurin ( $\mathrm{Cn}$ ) was shown to associate with the L-type $\mathrm{Ca}^{2+}$ channel, which is the major mediator of $\mathrm{Ca}^{2+}$ influx from the sarcoplasmic reticulum by activating $\mathrm{RyR}_{2}$ in cardiac myocytes [31]. The binding of CIB1 to $\alpha \operatorname{IIb} \beta 3$ is identified to inhibit phospholipase C (PLC)/IP signaling $[1,2,4]$. Of note, CIB1 is also reported to inhibit the $\mathrm{IP}_{3} \mathrm{R}-\mathrm{Ca}^{2+}$ release channel [32]. Binding of CIB1 to the N-terminal region of $\mathrm{IP}_{3} \mathrm{R}$ is reduced at low free $\left[\mathrm{Ca}^{2+}\right]$ and could be inhibited by mutations to EF hand-III or EF hand-IV, suggesting that $\mathrm{Ca}^{2+}$-binding is the trigger for the CIB1-IP ${ }_{3} \mathrm{R}$ interaction [7]. CIB1 interact with the intracellular C-terminal domain of rat sweet taste 1 receptor member 2 (TAS1R2) also reported to inhibit $\mathrm{IP}_{3} \mathrm{R}_{-} \mathrm{Ca}^{2+}$ release [4]. Until now, two recognized intracellular $\mathrm{Ca}^{2+}$ signaling pathways, integrin-IP $\mathrm{R}_{3}-\mathrm{Ca}^{2+}$ signaling and CD38$\mathrm{Ca}^{2+}$ signaling have been established. CD38 is a multifunctional ectoenzyme that catalyzes the synthesis and hydrolysis of cyclic ADP-ribose (cADPR) from nicotinamide adenine dinucleotide $\left(\mathrm{NAD}^{+}\right)$to ADP-ribose (ADPR) and nicotinic acid adenine dinucleotide phosphate (NAADP) [28, 33, 34]. Similar to integrin, a transmembrane CD38 also trigger intracellular $\mathrm{Ca}^{2+}$ signaling pathways [33]. In addition to $\mathrm{IP}_{3}$, cADPR and NAADP are already identified as important intracellular $\mathrm{Ca}^{2+}$ messengers, which elicit intracellular $\mathrm{Ca}^{2+}$ flux from both $\mathrm{ER}$ and endolysosome $[25,33,34]$. CD38 act as a $\mathrm{NAD}^{+}$dependent enzymes, which catalyzing the synthesis of cADPR and NAADP to mediate ER-Ca ${ }^{2+}$ and lysosome- $\mathrm{Ca}^{2+}$ signaling, respectively $[28,34]$. In addition to modulate $\mathrm{IP}_{3} \mathrm{R}^{-\mathrm{Ca}^{2+}}$ signaling, CIB1 is possibly also implicated in CD38 triggering $\mathrm{Ca}^{2+}$ signaling pathway. As summarized in Fig. 2, In IP 3 -ER-Ca ${ }^{2+}$ signaling, CIB1 acts as a partner of integrin, which affects the activation of PLC. As we known, $\mathrm{IP}_{3}$ is produced by the activation of PLC and it acts on $\mathrm{IP}_{3} \mathrm{R}$ to release $\mathrm{Ca}^{2+}$ from the ER stores. Besides, CIB1 also interact with the $\mathrm{C}$-terminal domain of TAS1R2 to inhibit $\mathrm{IP}_{3} \mathrm{R}_{-} \mathrm{Ca}^{2+}$ release. In CD38 triggering $\mathrm{Ca}^{2+}$ signaling pathway, it is interesting that whether CIB1 may also serve as an accessory protein of CD38, which synthesizes the second messengers, cADPR and NAADP. The synthetic cADPR and NAADP target to RYR and TPC/TRP-ML1, resulted in $\mathrm{Ca}^{2+}$ release from ER and endolysosome stores, respectively [25, 28, 34]. Furthermore, whether CIB1 is 


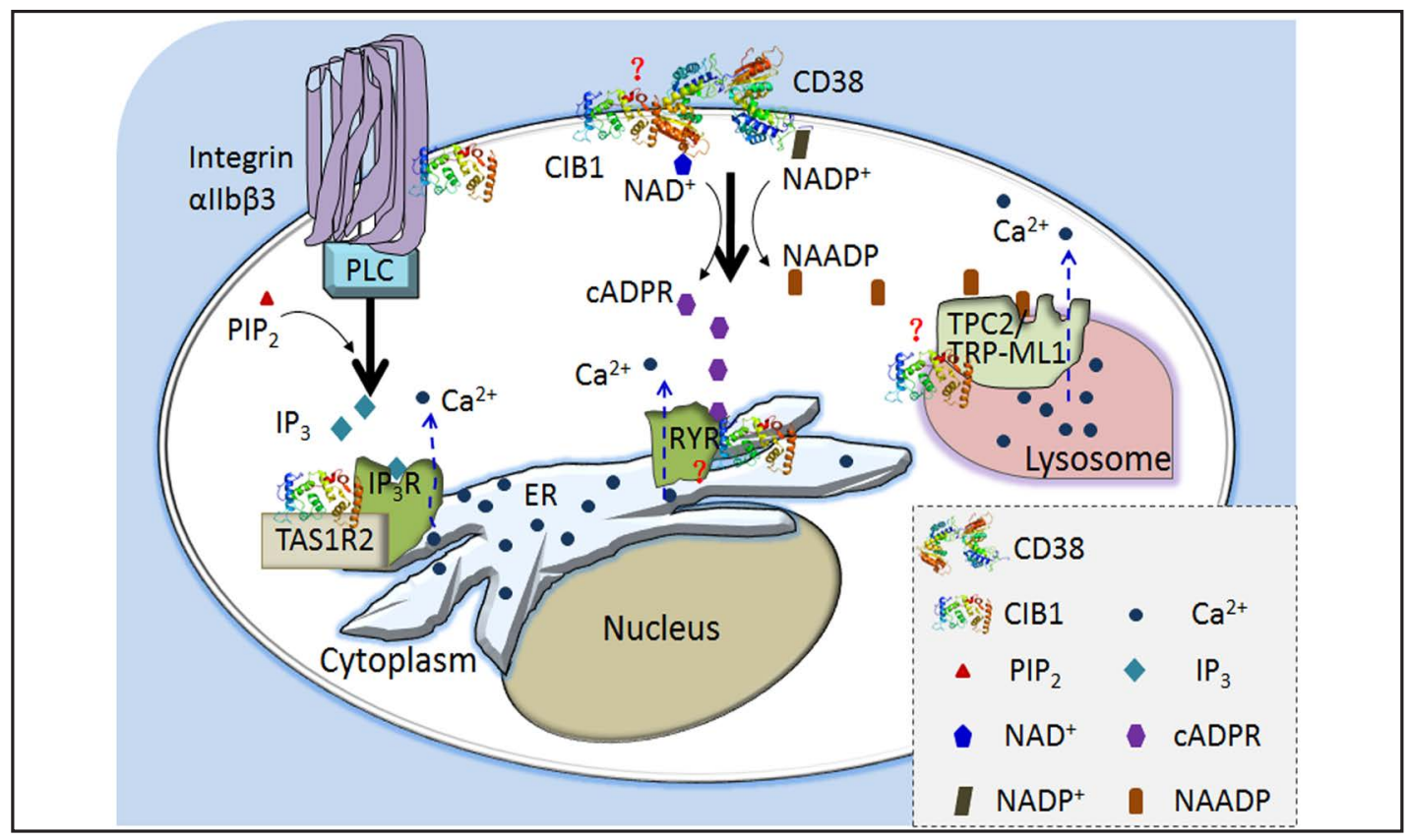

Fig. 2 The potential mechanism of CIB1 in intracellular $\mathrm{Ca}^{2+}$ signaling

Table. 2 The roles for CIB1 in tumor progression. Abbreviations: Acute myeloid leukemia (AML); colorectal cancer (CRC); hepatocellular Carcinoma (HCC); triple negative breast cancer (TNBC).

\begin{tabular}{|c|c|c|c|}
\hline Tumor or cell types & Targets & Potential mechanism & References \\
\hline MCF-7 cells & EDD, DNA-PKcs & DNA damage response; tumorigenesis & [56] \\
\hline T47D breast cancer & FAK, PAK1 & cancer cell migration & {$[69,70]$} \\
\hline H1299, MCF7 and HT1080 cells & $\begin{array}{l}\text { DNA-PKcs, } \\
\text { hTERT }\end{array}$ & telomere homeostasis; cancer cell proliferation & [53] \\
\hline TMK-1 cells & G1P3 & inhibit apoptosis & [18] \\
\hline $\begin{array}{l}\text { Melanoma or Lewis lung carcinoma } \\
\text { cells }\end{array}$ & PAK1, ERK1/2 & angiogenesis & {$[68,71]$} \\
\hline $\begin{array}{l}\text { HeLa, MCF- } 7 \text { and DU145 cells, lung } \\
\text { cancer, AML,CRC }\end{array}$ & Ras, SK1 & cell proliferation; antiapoptosis; tumor growth & {$[15,17]$} \\
\hline HCC and HepG2 cells & $\begin{array}{l}\text { PAK1, ERK1/2 } \\
\text { and ASK1 }\end{array}$ & cancer cell proliferation & [42] \\
\hline Breast cancer cells & PLK3 & calcium signaling, cancer cell proliferation & {$[20,44]$} \\
\hline $\begin{array}{l}\text { Breast, bladder, cervix and colorectal } \\
\text { cancer }\end{array}$ & PKD2 & $\begin{array}{c}\text { tumor cell invasion, tumor growth and } \\
\text { angiogenesis }\end{array}$ & {$[40]$} \\
\hline $\begin{array}{l}\text { Neuroblastoma and breast cancer } \\
\text { cells }\end{array}$ & $\begin{array}{c}\text { PI3K/AKT, } \\
\text { MEK/ERK and } \\
\text { PAK1 }\end{array}$ & cancer cell proliferation & [43] \\
\hline Kaposi's sarcoma & $\begin{array}{c}\text { EphrinA2, } \\
\text { ERK1/2 } \\
\text { DNA-PKcs, }\end{array}$ & virus entry & [78] \\
\hline Pancreatic cancer & $\begin{array}{l}\text { PLK3, Rac3, } \\
\text { Pax3, PS2 }\end{array}$ & cancer cell proliferation & [21] \\
\hline TNBC cells & $\begin{array}{l}\text { PI3K/AKT, } \\
\text { MEK/ERK }\end{array}$ & cancer cell proliferation & [41] \\
\hline
\end{tabular}

also likely to affect the RYR and TPC/TRP-ML1 activity directly may be the result of further mechanism that have not yet been elucidated. Of interest, whether CIB1 and the modulators in these two signaling pathways synergistically modulating intracellular $\mathrm{Ca}^{2+}$ signaling are not clear. Whether CIB1 also affects some other $\mathrm{Ca}^{2+}$ channels on cell membrane (such as NMDAR, L-type $\mathrm{Ca}^{2+}$ channel and NCX) are still need further investigation. Several studies suggested that targeting $\mathrm{Ca}^{2+}$ signaling possible serve as a potential strategy in cancer therapy [35-38]. Thus, gaining better understanding of the relationship between CIB1 and these $\mathrm{Ca}^{2+}$ modulators remain an important area to investigate in the future study.

\section{KARGER}




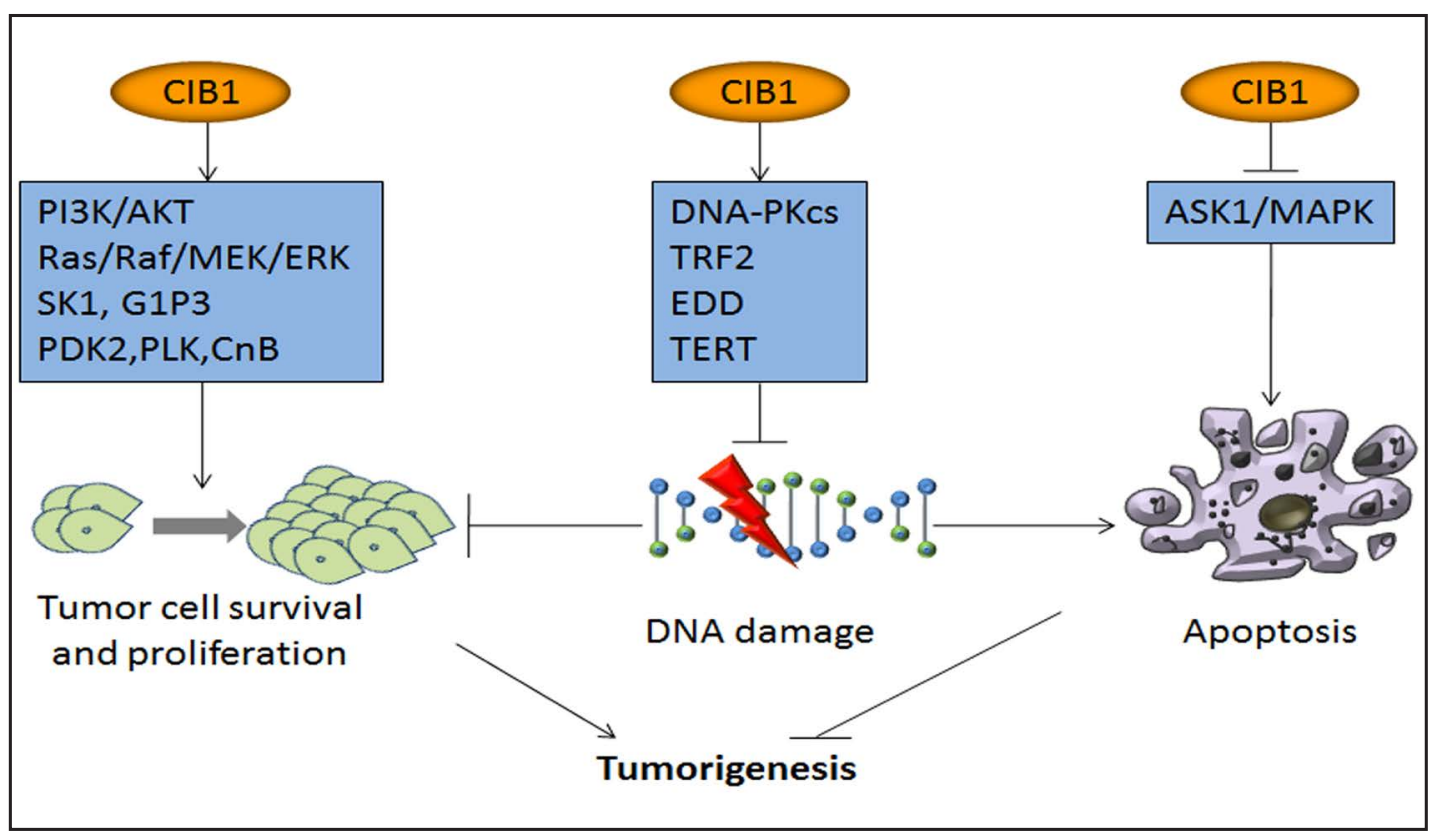

Fig. 3 The potential mechanism of CIB1 in tumorigenesis.

\section{The potential roles of CIB1 in tumor progression}

Recently, carcinogenesis of CIB1 is in the spotlight. Increasing evidence has suggested that CIB1 perform important roles in cell survival, cell proliferation, cell apoptosis and cell migration, thereby mediating tumor growth and angiogenesis [17, 20, 39-43]. CIB1 may serve an important role in tumorigenesis by regulating several kinase partners or oncogenic signaling (Table. 1, 2 and Fig. 3). The summary of these studies are described as below.

\section{CIB1 and tumor cell survival and death signaling}

Polo-like kinases (Plks), a family of serine/threonine kinases, have been shown to play key roles in regulation of cell cycle progression. So far, Plk1, Plk2, Plk3 and Plk4 proteins have been identified in the mammalian cells $[20,39,44]$. Plk2, also called serum-inducible protein kinase (Snk), is combined and inhibited by CIB1 [39, 45]. Plk3, also known as FGF-inducible kinase (Fnk), is coupled to the CIB1 in two-hybrid-analyses and coimmunoprecipitation assays [46]. The interaction between Plk3 and CIB1 might play a role in cancer progression. Later studies showed that CIB1 constitutively interacts with Plk3 and inhibits its activity in a $\mathrm{Ca}^{2+}$-dependent manner, thereby contributes to the regulation of the cell cycle [20]. Protein kinase D2 (PKD2), a member of the PKD family of serine/threonine kinases, has been reported as a potential promoter for tumor growth and angiogenesis [40, 47]. Armacki et al. suggested that a novel splice variant of CIB1 (called CIB1a), which regulates tumor cell invasion, tumor growth and angiogenesis by mediating PKD-induced the secretion of vascular endothelial growth factor [40]. SK1 plays an important role in cell proliferation, protection from apoptosis, and oncogenic rat sarcoma (Ras)-mediated neoplastic transformation $[15,17,48]$. Study showed that CIB1 interacts with SK1 and promotes the translocation of SK1 from cytoplasm to plasma membrane, mediating activation of SK1 and in turn anti-apoptotic signaling through the nuclear factor kappa-light-chain-enhancer of activated B cells (NF- $\kappa B$ ) pathway [15]. As we known, SK1 is a downstream mediator of oncogenic signaling by Ras since chemical inhibitors of SK or a dominant-negative SK1 attenuated Ras-induced neoplastic transformation [48, 49]. Besides, studies indicated that oncogenic Ras induced plasma membrane localization of SK1 [17, 50]. Thus, CIB1 serves as

\section{KARGER}


an important effector of oncogenic signaling by Ras through the enhancement of subcellular localization of SK1 to the cell membrane [17]. Phosphatidyl inositol 3-kinase (PI3K) and extracellular regulated protein kinases (ERK) are involved in cellular functions such as cell growth, proliferation [51,52]. CIB1 is also implicated in cell survival and proliferation by modulating PI3K/AKT and MEK/ERK oncogenic signaling [41, 42]. Leisner et al. have been identified that CIB1 depletion increased nuclear distribution of GAPDH by interrupting AKT and ERK signaling, leading to caspase-independent cell death and proliferation inhibition [43]. Besides, CIB1 can associate with the catalytic subunit of human telomerase reverse transcriptase (hTERT), stimulating telomerase activity and telomere lengthening [53, 54]. CIB1 is required for the association between telomeric repeat-binding factor 2 (TRF2) and DNA-protein kinase catalytic subunit (DNA-PKcs), the interplay of these three proteins may provide a mechanism for the recruitment of DNA-PKcs to telomeres [54]. The interaction between CIB1 and DNA-PKcs also affects DNA-PKcs related DNA damage [53, 55]. Moreover, being a binding partner of E3 ubiquitin-protein ligase UBR5 (EDD), CIB1 is a possible target for E3-mediated degradation and potentially involved in DNA damage signaling [56]. Study showed that CIB1 inhibits apoptosis signal-regulating kinase 1 (ASK1) activity both in vitro and in vivo, thereby negatively regulates stress-activated mitogen-activated protein kinase (MAPK) signaling pathways and apoptosis [57]. The mitochondria serve important roles in intrinsic apoptotic pathway [58, 59]. A mitochondrial localized G1P3 (also known as interferon alpha-inducible protein 6 (IFI6) or interferon-induced protein 6-16) has been shown to inhibit mitochondrial-mediated apoptosis in gastric cancer cell line TMK-1 cells [18]. This anti-apoptotic function is mediated by interacting with CIB1, thereby inhibit the depolarization of mitochondrial membrane potential, release of cytochrome c [18]. Although overexpression of CIB1 and/or PS2 promotes cell death in vitro, but no published data to confirm the role of CIB1 in cancer cell apoptosis $[13,18]$, further studies are needed to conclude the involvement in the anti-apoptotic activity. As summarized in Fig. 3, PI3K/ AKT, Ras/Raf/MEK/ERK, Plks, PDK2, SK1 and G1P3 may be potential oncogenic signaling in CIB1-driven tumor progression. As an important effector of DNA damage signaling, CIB1 may effect tumor progression by regulating the function of DNA-PKcs, TRF2, EDD and TERT. Furthermore, inhibitions of tumor cells apoptosis by inhibiting ASK1/MAPK signaling are also involved in CIB1-induced carcinogenesis.

\section{CIB1 and tumor cell migration and angiogenesis}

Moreover, cell migration plays an essential role in tumor growth and metastasis. CIB1 is also involved in tumor metastasis by effecting tumor cell migration and spreading [7]. Until now, multiple studies have indicated that CIB1 serve important roles in regulating platelet integrin activity, cell adhesion and migration by interacting with at least six binding partners, including $\alpha I I b \beta 3$, the coagulation factor VIII (FVIII), Wiskot-Aldrich syndrome protein (WASP), the small GTPase Rac3, P21-activatd kinases 1 (PAK1) and focal adhesion kinase (FAK). As a major adhesion receptors, integrin control many normal cellular processes, including migration, growth, differentiation, and proliferation [60]. Studies has suggested that CIB1 is coupled to cytoplasmic domain of $\alpha \operatorname{IIb} \beta 3$, thereby blocks $\alpha \operatorname{IIb} \beta 3$ activation and in turn platelet aggregation $[1,2]$. Further study indicated that CIB1 could bind to all integrin complexes and act as a broad regulator of integrin function [3]. CIB1 also interacts with the FVIII in 227-336 regions, suggesting that CIB1 pay important roles in coagulation [24]. Base on the relationship between CIB1 and $\alpha \mathrm{IIb} \beta 3$, CIB1 is also involved in cell migration [61]. WASP binding to CIB1 affects the affinity of $\alpha \operatorname{IIb} \beta 3$ for fibrinogen (also called factor I), a soluble plasma glycoprotein is converted by thrombin into fibrin during blood coagulation [62-64]. CIB1 can bind to $\mathrm{N}$ terminus of the WASP and recruit it to $\alpha \operatorname{IIb} \beta 3$, increasing $\alpha \operatorname{IIb} \beta 3$-mediated cell adhesion in stimulated platelets [65]. Tsuboi et al. advanced that inhibition of WASPCIB1 binding by streptolysin 0 decreases $\alpha \operatorname{Ilb} \beta 3$ affinity for fibrinogen [65]. It is reported that CIB1 interacts with the small GTPase Rac3 and promotes $\alpha$ IIb $\beta 3$-mediated adhesion and spreading of cells through the fibrinogen receptor, such as $\alpha I I b \beta 3$ [66]. As a downstream of Rac3, PAK1 is another key factor in cell migration. Multiple studies have indicated that 


\section{Cellular Physiology Cell Physiol Biochem 2017;43:1413-1424

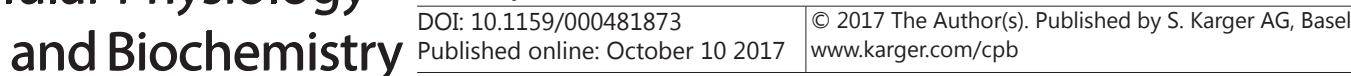 \\ Wang et al.: CIB1 and Cancer}

CIB1 is essential for PAK1 activation both in vitro and vivo, which further suggested that CIB1-PAK1 interaction is involved in cell migration [67-69]. Naik et al. suggested that CIB1 positively regulates cell migration and is necessary for the recruitment of FAK (also known as protein tyrosine kinase 2, PTK2, a key regulator in focal complex formation) to the focal adhesions. Furthermore, CIB1induced cell migration is dependent on MAPK signaling and its function is attenuated by PAK1 [69]. Overexpression of CIB1 resulted

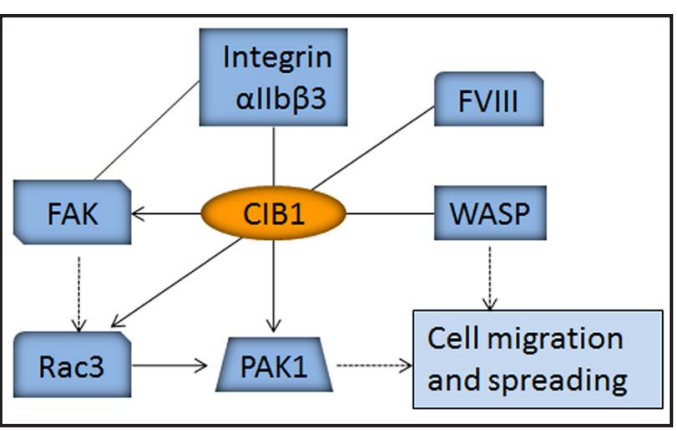

Fig. 4 The roles of CIB1 in cell migration. in cell migration on fibronectin and ERK1/2 MAPK activation [69]. Moreover, by using Chinese hamster ovary cells as model, study showed that CIB1 induces cell migration by binding of FAK and increasing its activity. Overexpression of dominant-negative FAK and CIB1 inhibited cell migration completely [70]. Zayed et al. also found that CIB1 play a critical role in facilitating tumor growth and tumor-induced angiogenesis $[68,71]$. As shown in Fig. 4, CIB1 can interact with the N-terminus of $\alpha \operatorname{IIb} \beta 3$ subsequent to integrin activation. CIB1 also bind to WASP and recruit it to $\alpha \operatorname{IIb} \beta 3$, which further promoting cell adhesion and spreading. The binding of CIB1 to FAK will also enhance FAK activation [64], and thereby triggering Rac3 and PAK1 induced adhesion and spreading.

In conclusion, CIB1 is widely up-regulated across a diverse range of human cancers. As an emerging potential oncogene [17], CIB1 may affect tumor progression by modulating various processes, including $\mathrm{Ca}^{2+}$ signaling, apoptosis, cell cycle and proliferation, cell migration and spreading, telomerase activity and DNA damage. Taken together, there are several potential mechanisms of CIB1 in cancer, including (i) promoting tumor cell cycle and proliferation, (ii) inhibiting tumor cell apoptosis, and (iii) mediating tumor cell migration and angiogenesis. Thus, CIB1 might become a good potential target for cancer therapy. Confirming the interaction mechanism between CIB1 and its interacting partners might provide the potential strategies for preventing cancers.

\section{CIB1 and other pathological or physiological process}

CIB1 is a versatile protein by interacting with more than 35 binding partners so far [7]. Of interest, CIB1 is involved in embryogenesis, neural development, AD etc. SCG10 protein (stathmin2), a microtubule-destabilizing factor, which is implicated in neuronal growth during brain development by tied up to the C-terminal of CIB1 and inhibited SCG10-mediated neurite outgrowth [72]. Whitehouse et al. have indicated that CIB1 interacts with NBR1 (named as next to BRCA1) and fasciculation and elongation protein zeta-1 (FEZ1) by using both the yeast two-hybrid assay and coimmunoprecipitation studies [73]. They also identified the subcellular co-localization of CIB1, NBR1 and FEZ1 proteins by immunofluorescence analysis, and speculated that the interactions between these proteins possible an important event in brain development [73]. A member of the paired class homeodomain family of transcription factors, paired box 3 protein (PAX3) [74], has been demonstrated to implicated in brain development by specifically fastening with CIB1 [75]. It is well established that Presenilin 1/2 (PS1/2) are important ageing genes. CIB1 has been demonstrated to fasten with PS2 and increase cell death [13]. By site-directed mutagenesis, Zhu et al. suggested that the interaction between CIB1 and PS2 is regulated by $\mathrm{Ca}^{2+}$ binding sequences in EF-hands III and IV [14]. Continues study showed that these binding appear to be in $\mathrm{Ca}^{2+}$ independent manner [22]. Moreover, the interaction between CIB1 and Fnk/Snk suggested that CIB1 play vital roles in synaptic plasticity [39]. Study has also demonstrated that CIB1 is associated with hTERT [53], and presented in human forebrain and altered distribution in AD brain [23], further suggesting that CIB1 might play important roles in $\operatorname{AD}[13,14,22,23]$. As

\section{KARGER}




\section{Cellular Physiology Cell Physiol Biochem 2017;43:1413-1424

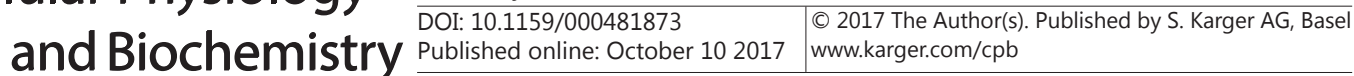 \\ Wang et al.: CIB1 and Cancer}

shown in Fig. 5, CIB1 control brain development by interact with a variety of partners, including NBR1, SCG10, FEZ1 and PAX3. CIB1 is involved in AD by modulating PS1/2, TERT and Fnk/ Snk signaling. Moreover, CIB1 is also related to spermatogenesis. Downregulation of CIB1 in the sperm of patients with oligoasthenozoospermia [76], reflected that CIB1 may be involved in male subfertility $[19,76]$. CIB1 binds to TAS1R2 also suggested that CIB1 might be also effect taste or gustation functions [4]. CIB1 also serve as a potential effector molecule in

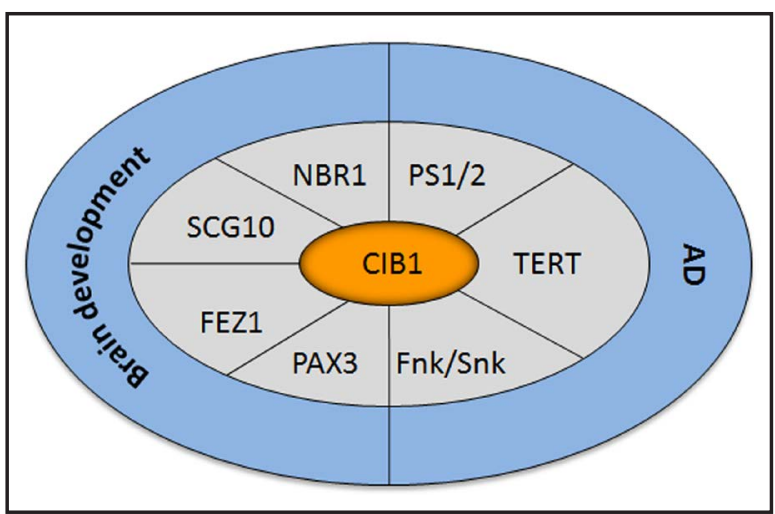

Fig. 5 The potential roles of CIB1 in brain development and AD. virus infection, such as human herpes virus 8 and human immunodeficiency virus type-1 [77, 78]. It is demonstrated that CIB1 interacts with EphrinA2 (EphA2) and increase Kaposi's sarcoma-associated herpes virus infection in 293 cells [78]. CIB1 is high expressed in human and rat heart and necessary for cardiac hypertrophy [16, 30]. CIB1 and Cn expression was increased in atrial fibrillation atrial tissue, suggesting that CIB1 may be involved in the pathogenesis of valvular heart disease [79]. As we known, structure determines function. To get insight into the function of CIB1, the structure of CIB1 has been explored extensively by sequence analysis, nuclear magnetic resonance spectroscopy (NMR), circular dichroism or X-ray crystallography [6$8,10,80]$. Thus, we believed that along with the further analysis of CIB1 structure, more and more CIB1 partners and the precise mechanisms for multiple function of CIB1 will be identified in the future.

\section{Conclusion}

In summary, as a multifunctional protein, CIB1 serving not only as a $\mathrm{Ca}^{2+}$ modulating protein, most surprisingly, but also as an important potential tumor promoting factor. Here we discussed the plausible mechanism of CIB1 in intracellular $\mathrm{Ca}^{2+}$ signaling conduction and paid more attention to an important pro-tumorigenic role for CIB1. The review of the signaling mechanism for CIB1 in tumor progression will highlight the great potential target for cancer therapy.

\section{Abbreviations}

CIB1 (Calcium and integrin-binding protein 1); $\alpha \operatorname{IIb} \beta 3$ (Integrin alpha-IIb/beta3); $\mathrm{IP}_{3} \mathrm{R}$ (Inositol 1, 4,5-trisphosphate receptor); RyR (Ryanodine receptors); $\mathrm{CnB}$ (Calcineurin B); CaM (Calmodulin); AD (Alzheimer's disease, ); TPCs (Two-pore channels ); TRP-ML1 (Transient receptor potential mucolipin-1); PLC (Phospholipase C); TAS1R2 (taste 1 receptor member 2); cADPR (Cyclic ADP-ribose ); NAADP (Nicotinic acid adenine dinucleotide phosphate); Plks (Polo-like kinases); Snk (Serum-inducible protein kinase); Fnk (FGF-inducible kinase); PKD2 (Protein kinase D2); SK1 (Sphingosine kinase 1); ASK1 (Apoptosis signal-regulating kinase 1); IFI6 (Interferon alpha-inducible protein 6); hTERT (Human telomerase reverse transcriptase); DNA-PKcs (DNA-protein kinase catalytic subunit); EDD (E3 ubiquitinprotein ligase UBR5 ); FVIII (Coagulation Factor VIII); WASP (Wiskot-Aldrich syndrome protein); PAK1 (P21-activated kinases 1); FAK (Focal adhesion kinase); FEZ1 (Fasciculation and elongation protein zeta-1); PAX3 (Paired box 3 protein ); PS1/2 (Presenilin); EphA2 (EphrinA2); HCC (Hepatocellular carcinoma). 


\section{Cellular Physiology Cell Physiol Biochem 2017;43:1413-1424

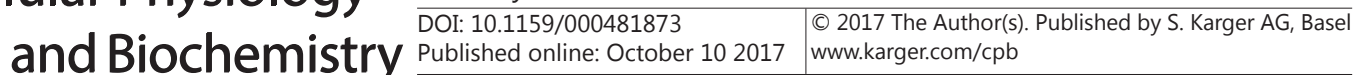

Wang et al.: CIB1 and Cancer

\section{Acknowledgements}

This research is supported by the National Natural Science Foundation of China (31700736), Hubei Province Natural Science Foundation of China (2016CFB180), Hubei Province Health and Family Planning Scientific Research Project (WJ2016Y07), Hubei Province Scientific and Technological Research Project (Q20171306), Jingzhou Science and Technology Development Planning Project (JZKJ15063), the Program for Medical Talents of Hubei Province, the Fundamental Research Funds for the Central Universities (531107040909, 14700502044001), the Development Fund from School of Medicine in Yangtze University, the Yangtze Fund for Youth Teams of Science and Technology Innovation (2016CQT04) and the College Students Innovative Entrepreneurial Training Program in Yangtze University (2016133). We are grateful to Professor Hongwu Xing for assistance in editing of the manuscript.

\section{Disclosure Statement}

The authors do not have conflict of interest.

\section{References}

1 Naik UP, Patel PM, Parise LV: Identification of a novel calcium-binding protein that interacts with the integrin alphaIIb cytoplasmic domain. J Biol Chem 1997;272:4651-4654.

-2 Yuan W, Leisner TM, McFadden AW, Wang Z, Larson MK, Clark S, Boudignon-Proudhon C, Lam SC, Parise LV: CIB1 is an endogenous inhibitor of agonist-induced integrin alphallbbeta3 activation. J Cell Biol 2006;172:169-175.

- 3 Freeman TC, Jr., Black JL, Bray HG, Dagliyan O, Wu YI, Tripathy A, Dokholyan NV, Leisner TM, Parise LV: Identification of novel integrin binding partners for calcium and integrin binding protein 1 (CIB1): structural and thermodynamic basis of CIB1 promiscuity. Biochemistry 2013;52:7082-7090.

4 Hennigs JK, Burhenne N, Stahler F, Winnig M, Walter B, Meyerhof W, Schmale H: Sweet taste receptor interacting protein CIB1 is a general inhibitor of InsP3-dependent Ca2+ release in vivo. J Neurochem 2008;106:2249-2262.

5 Rusnak F, Mertz P: Calcineurin: form and function. Physiol Rev 2000;80:1483-1521.

6 Gentry HR, Singer AU, Betts L, Yang C, Ferrara JD, Sondek J, Parise LV: Structural and biochemical characterization of CIB1 delineates a new family of EF-hand-containing proteins. J Biol Chem 2005;280:8407-8415.

7 Leisner TM, Freeman TC, Black JL, Parise LV: CIB1: a small protein with big ambitions. FASEB J 2016;30:2640-2650.

8 Huang H, Ishida H, Yamniuk AP, Vogel HJ: Solution structures of Ca2+-CIB1 and Mg2+-CIB1 and their interactions with the platelet integrin alphaIIb cytoplasmic domain. J Biol Chem 2011;286:17181-17192.

-9 Gifford JL, Walsh MP, Vogel HJ: Structures and metal-ion-binding properties of the Ca2+-binding helix-loophelix EF-hand motifs. Biochem J 2007;405:199-221.

10 Yamniuk AP, Anderson KL, Fraser ME, Vogel HJ: Auxiliary Ca2+ binding sites can influence the structure of CIB1. Protein Sci 2009;18:1128-1134.

11 Yamniuk AP, Nguyen LT, Hoang TT, Vogel HJ: Metal ion binding properties and conformational states of calcium- and integrin-binding protein. Biochemistry 2004;43:2558-2568.

$>12$ Sobczak A, Blazejczyk M, Piszczek G, Zhao G, Kuznicki J, Wojda U: Calcium-binding calmyrin forms stable covalent dimers in vitro, but in vivo is found in monomeric form. Acta Biochim Pol 2005;52:469-476.

13 Stabler SM, Ostrowski LL, Janicki SM, Monteiro MJ: A myristoylated calcium-binding protein that preferentially interacts with the Alzheimer's disease presenilin 2 protein. J Cell Biol 1999;145:1277-1292.

14 Zhu J, Stabler SM, Ames JB, Baskakov I, Monteiro MJ: Calcium binding sequences in calmyrin regulates interaction with presenilin-2. Exp Cell Res 2004;300:440-454.

15 Jarman KE, Moretti PA, Zebol JR, Pitson SM: Translocation of sphingosine kinase 1 to the plasma membrane is mediated by calcium- and integrin-binding protein 1. J Biol Chem 2010;285:483-492. 


\section{Cellular Physiology Cell Physiol Biochem 2017;43:1413-1424 \begin{tabular}{ll|l} 
DOI: 10.1159/000481873 & & $\begin{array}{l}\text { O 2017 The Author(s). Published by S. Karger AG, Basel } \\
\text { www.karger.com/cpb }\end{array}$
\end{tabular}}

Wang et al.: CIB1 and Cancer

16 Heineke J, Auger-Messier M, Correll RN, Xu J, Benard MJ, Yuan W, Drexler H, Parise LV, Molkentin JD: CIB1 is a regulator of pathological cardiac hypertrophy. Nat Med 2010;16:872-879.

-17 Zhu W, Gliddon BL, Jarman KE, Moretti PAB, Tin T, Parise LV, Woodcock JM, Powell JA, Ruszkiewicz A, Pitman MR, Pitson SM: CIB1 contributes to oncogenic signalling by Ras via modulating the subcellular localisation of sphingosine kinase 1. Oncogene 2017;36:2619-2627.

18 Tahara E, Jr., Tahara H, Kanno M, Naka K, Takeda Y, Matsuzaki T, Yamazaki R, Ishihara H, Yasui W, Barrett JC, Ide T, Tahara E: G1P3, an interferon inducible gene 6-16, is expressed in gastric cancers and inhibits mitochondrial-mediated apoptosis in gastric cancer cell line TMK-1 cell. Cancer Immunol Immunother 2005;54:729-740.

19 Yuan W, Leisner TM, McFadden AW, Clark S, Hiller S, Maeda N, O’Brien DA, Parise LV: CIB1 is essential for mouse spermatogenesis. Mol Cell Biol 2006;26:8507-8514.

20 Naik MU, Pham NT, Beebe K, Dai W, Naik UP: Calcium-dependent inhibition of polo-like kinase 3 activity by CIB1 in breast cancer cells. Int J Cancer 2011;128:587-596.

21 Nagayoshi Y, Nakamura M, Matsuoka K, Ohtsuka T, Mori Y, Kono H, Aso T, Ideno N, Takahata S, Ryo A, Takeda H, Ito T, Oda Y, Endo Y, Sawasaki T, Tanaka M: Profiling of autoantibodies in sera of pancreatic cancer patients. Ann Surg Oncol 2014;21:S459-465.

-22 Blazejczyk M, Wojda U, Sobczak A, Spilker C, Bernstein HG, Gundelfinger ED, Kreutz MR, Kuznicki J: $\mathrm{Ca} 2+-$ independent binding and cellular expression profiles question a significant role of calmyrin in transduction of Ca2+-signals to Alzheimer's disease-related presenilin 2 in forebrain. Biochim Biophys Acta 2006;1762:66-72.

23 Bernstein HG, Blazejczyk M, Rudka T, Gundelfinger ED, Dobrowolny H, Bogerts B, Kreutz MR, Kuznicki J, Wojda U: The Alzheimer disease-related calcium-binding protein Calmyrin is present in human forebrain with an altered distribution in Alzheimer's as compared to normal ageing brains. Neuropathol Appl Neurobiol 2005;31:314-324.

24 Fang X, Chen C, Wang Q Gu J, Chi C: The interaction of the calcium- and integrin-binding protein (CIBP) with the coagulation factor VIII. Thromb Res 2001;102:177-185.

25 Guse AH, Lee HC: NAADP: a universal Ca2+ trigger. Sci Signal 2008;1:re10.

-26 Zhang F, Jin S, Yi F, Li PL: TRP-ML1 functions as a lysosomal NAADP-sensitive Ca2+release channel in coronary arterial myocytes. J Cell Mol Med 2009;13:3174-3185.

27 Wang X, Song J, Wu Z, Fan B, Mode X: Dual Roles of CD38 in Autophagy. Yangtze Medicine 2017;01:8-19.

28 Gerasimenko JV, Charlesworth RM, Sherwood MW, Ferdek PE, Mikoshiba K, Parrington J, Petersen OH, Gerasimenko OV: Both RyRs and TPCs are required for NAADP-induced intracellular $\mathrm{Ca}(2)(+)$ release. Cell Calcium 2015;58:237-245.

-29 Zhu S, Xu T, Luo Y, Zhang Y, Xuan H, Ma Y, Pan D, Li D, Zhu H: Luteolin Enhances Sarcoplasmic Reticulum Ca2+-ATPase Activity through p38 MAPK Signaling thus Improving Rat Cardiac Function after Ischemia/ Reperfusion. Cell Physiol Biochem 2017;41:999-1010.

-30 Frost RJ, Olson EN: Separating the good and evil of cardiac growth by CIB1 and calcineurin. Cell Metab 2010;12:205-206.

-31 Tandan S, Wang Y, Wang TT, Jiang N, Hall DD, Hell JW, Luo X, Rothermel BA, Hill JA: Physical and functional interaction between calcineurin and the cardiac L-type Ca2+ channel. Circ Res 2009;105:51-60.

32 White C, Yang J, Monteiro MJ, Foskett JK: CIB1, a ubiquitously expressed Ca2+-binding protein ligand of the InsP3 receptor Ca2+ release channel. J Biol Chem 2006;281:20825-20833.

-33 Howard M, Grimaldi JC, Bazan JF, Lund FE, Santos-Argumedo L, Parkhouse RM, Walseth TF, Lee HC: Formation and hydrolysis of cyclic ADP-ribose catalyzed by lymphocyte antigen CD38. Science 1993;262:1056-1059.

-34 Aarhus R, Graeff RM, Dickey DM, Walseth TF, Lee HC: ADP-ribosyl cyclase and CD38 catalyze the synthesis of a calcium-mobilizing metabolite from NADP. J Biol Chem 1995;270:30327-30333.

35 Cui C, Merritt R, Fu L, Pan Z: Targeting calcium signaling in cancer therapy. Acta Pharm Sin B 2017;7:3-17.

-36 Zhang Y, Zhang T, Wu C, Xia Q, Xu D: ASIC1a mediates the drug resistance of human hepatocellular carcinoma via the Ca2+/PI3-kinase/AKT signaling pathway. Lab Invest 2017;97:53-69.

-37 Davis FM, Azimi I, Faville RA, Peters AA, Jalink K, Putney JW, Jr., Goodhill GJ, Thompson EW, RobertsThomson SJ, Monteith GR: Induction of epithelial-mesenchymal transition (EMT) in breast cancer cells is calcium signal dependent. Oncogene 2014;33:2307-2316. 


\section{Cellular Physiology Cell Physiol Biochem 2017;43:1413-1424

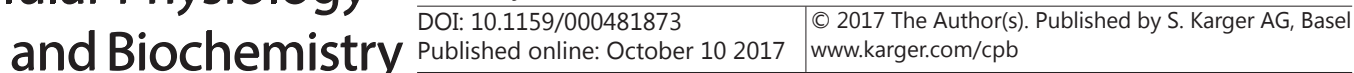

Wang et al.: CIB1 and Cancer

-38 Azimi I, Roberts-Thomson SJ, Monteith GR: Calcium influx pathways in breast cancer: opportunities for pharmacological intervention. Br J Pharmacol 2014;171:945-960.

-39 Kauselmann G, Weiler M, Wulff P, Jessberger S, Konietzko U, Scafidi J, Staubli U, Bereiter-Hahn J, Strebhardt K, Kuhl D: The polo-like protein kinases Fnk and Snk associate with a $\mathrm{Ca}(2+)$ - and integrin-binding protein and are regulated dynamically with synaptic plasticity. EMBO J 1999;18:5528-5539.

40 Armacki M, Joodi G, Nimmagadda SC, de Kimpe L, Pusapati GV, Vandoninck S, Van Lint J, Illing A, Seufferlein T: A novel splice variant of calcium and integrin-binding protein 1 mediates protein kinase D2-stimulated tumour growth by regulating angiogenesis. Oncogene 2014;33:1167-1180.

-41 Black JL, Harrell JC, Leisner TM, Fellmeth MJ, George SD, Reinhold D, Baker NM, Jones CD, Der CJ, Perou CM, Parise LV: CIB1 depletion impairs cell survival and tumor growth in triple-negative breast cancer. Breast Cancer Res Treat 2015;152:337-346.

42 Tong JR, Zhou HC, He F, Gao Y, Yang XQ Luo ZM, Zhang H, Zeng JY, Wang Y, Huang YH, Zhang JL, Sun LH, He GL: Proteomic identification of CIB1 as a potential diagnostic factor in hepatocellular carcinoma. J Biosciences 2011;36:659-668.

43 Leisner TM, Moran C, Holly SP, Parise LV: CIB1 prevents nuclear GAPDH accumulation and non-apoptotic tumor cell death via AKT and ERK signaling. Oncogene 2013;32:4017-4027.

44 Naik MU, Naik UP: Calcium- and integrin-binding protein 1 regulates microtubule organization and centrosome segregation through polo like kinase 3 during cell cycle progression. Int J Biochem Cell Biol 2011;43:120-129.

45 Ma S, Liu MA, Yuan YL, Erikson RL: The serum-inducible protein kinase Snk is a G1 phase polo-like kinase that is inhibited by the calcium- and integrin-binding protein CIB. Mol Cancer Res 2003;1:376-384.

-46 Holtrich U, Wolf G, Yuan J, Bereiter-Hahn J, Karn T, Weiler M, Kauselmann G, Rehli M, Andreesen R, Kaufmann M, Kuhl D, Strebhardt K: Adhesion induced expression of the serine/threonine kinase Fnk in human macrophages. Oncogene 2000;19:4832-4839.

-47 Hao Q, Wang L, Zhao ZJ, Tang H: Identification of protein kinase D2 as a pivotal regulator of endothelial cell proliferation, migration, and angiogenesis. J Biol Chem 2009;284:799-806.

48 Xia P, Gamble JR, Wang L, Pitson SM, Moretti PA, Wattenberg BW, D’Andrea RJ, Vadas MA: An oncogenic role of sphingosine kinase. Curr Biol 2000;10:1527-1530.

49 Pitson SM, Moretti PA, Zebol JR, Xia P, Gamble JR, Vadas MA, D’Andrea RJ, Wattenberg BW: Expression of a catalytically inactive sphingosine kinase mutant blocks agonist-induced sphingosine kinase activation. A dominant-negative sphingosine kinase. J Biol Chem 2000;275:33945-33950.

-50 Gault CR, Eblen ST, Neumann CA, Hannun YA, Obeid LM: Oncogenic K-Ras regulates bioactive sphingolipids in a sphingosine kinase 1-dependent manner. J Biol Chem 2012;287:31794-31803.

51 Castaing-Berthou A, Malet N, Radojkovic C, Cabou C, Gayral S, Martinez LO, Laffargue M: PI3Kbeta Plays a Key Role in Apolipoprotein A-I-Induced Endothelial Cell Proliferation Through Activation of the Ecto-F1ATPase/P2Y1 Receptors. Cell Physiol Biochem 2017;42:579-593.

52 Wang X, Chen WR, Xing D: A pathway from JNK through decreased ERK and Akt activities for FOXO3a nuclear translocation in response to UV irradiation. J Cell Physiol 2012;227:1168-1178.

53 Lee GE, Yu EY, Cho CH, Lee J, Muller MT, Chung IK: DNA-protein kinase catalytic subunit-interacting protein KIP binds telomerase by interacting with human telomerase reverse transcriptase. J Biol Chem 2004;279:34750-34755.

54 Khadka P, Lee JH, Baek SH, Oh SY, Chung IK: DNA-PKcs-interacting protein KIP binding to TRF2 is required for the maintenance of functional telomeres. Biochem J 2014;463:19-30.

55 Cen WJ, Pan Y, Li WX, Yang SQ: Comparison of DNA-dependent protein kinase catalytic subunit expression in two lung adenocarcinoma cell lines with different radiosensitivity. Nan Fang Yi Ke Da Xue Xue Bao 2009;29:2241-2243.

56 Henderson MJ, Russell AJ, Hird S, Munoz M, Clancy JL, Lehrbach GM, Calanni ST, Jans DA, Sutherland RL, Watts CK: EDD, the human hyperplastic discs protein, has a role in progesterone receptor coactivation and potential involvement in DNA damage response. J Biol Chem 2002;277:26468-26478.

57 Yoon KW, Cho JH, Lee JK, Kang YH, Chae JS, Kim YM, Kim J, Kim EK, Kim SE, Baik JH, Naik UP, Cho SG, Choi EJ: CIB1 functions as a $\mathrm{Ca}(2+)$-sensitive modulator of stress-induced signaling by targeting ASK1. Proc Natl Acad Sci U S A 2009;106:17389-17394.

58 Wang X, Xing D, Liu L, Chen WR: BimL directly neutralizes Bcl-xL to promote Bax activation during UVinduced apoptosis. FEBS Lett 2009;583:1873-1879. 


\section{Cellular Physiology Cell Physiol Biochem 2017;43:1413-1424

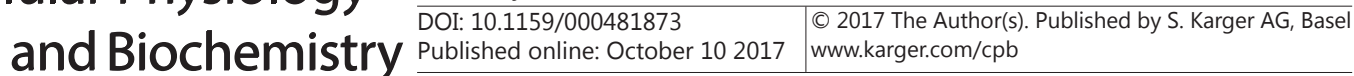 \\ Wang et al.: CIB1 and Cancer}

59 Wang X, He X, Hu S, Sun A, Lu C: Involvement of Bim in Photofrin-mediated photodynamically induced apoptosis. Cell Physiol Biochem 2015;35:1527-1536.

60 Hynes RO: Integrins: bidirectional, allosteric signaling machines. Cell 2002;110:673-687.

61 Shock DD, Naik UP, Brittain JE, Alahari SK, Sondek J, Parise LV: Calcium-dependent properties of CIB binding to the integrin alphaIIb cytoplasmic domain and translocation to the platelet cytoskeleton. Biochem J 1999;342 Pt 3:729-735.

62 Litvinov RI, Farrell DH, Weisel JW, Bennett JS: The Platelet Integrin alphaIIbbeta3 Differentially Interacts with Fibrin Versus Fibrinogen. J Biol Chem 2016;291:7858-7867.

-63 Duval C, Ariens RAS: Fibrinogen splice variation and cross-linking: Effects on fibrin structure/function and role of fibrinogen gamma' as thrombomobulin II. Matrix Biol 2017;60-61:8-15.

64 Naik MU, Naik TU, Summer R, Naik UP: Binding of CIB1 to the alphaIIb tail of alphallbbeta3 is required for FAK recruitment and activation in platelets. PLoS One 2017;12:e0176602.

65 Tsuboi S, Nonoyama S, Ochs HD: Wiskott-Aldrich syndrome protein is involved in alphaIIb beta3-mediated cell adhesion. EMBO Rep 2006;7:506-511.

66 Haataja L, Kaartinen V, Groffen J, Heisterkamp N: The small GTPase Rac3 interacts with the integrinbinding protein CIB and promotes integrin alpha(IIb)beta(3)-mediated adhesion and spreading. J Biol Chem 2002;277:8321-8328.

67 Leisner TM, Liu M, Jaffer ZM, Chernoff J, Parise LV: Essential role of CIB1 in regulating PAK1 activation and cell migration. J Cell Biol 2005;170:465-476.

68 Zayed MA, Yuan W, Chalothorn D, Faber JE, Parise LV: Tumor growth and angiogenesis is impaired in CIB1 knockout mice. J Angiogenes Res 2010;2:17.

69 Naik MU, Naik UP: Contra-regulation of calcium- and integrin-binding protein 1-induced cell migration on fibronectin by PAK1 and MAP kinase signaling. J Cell Biochem 2011;112:3289-3299.

70 Naik MU, Naik UP: Calcium-and integrin-binding protein regulates focal adhesion kinase activity during platelet spreading on immobilized fibrinogen. Blood 2003;102:3629-3636.

-71 Zayed MA, Yuan W, Leisner TM, Chalothorn D, McFadden AW, Schaller MD, Hartnett ME, Faber JE, Parise LV: CIB1 regulates endothelial cells and ischemia-induced pathological and adaptive angiogenesis. Circ Res 2007;101:1185-1193.

72 Sobczak A, Debowska K, Blazejczyk M, Kreutz MR, Kuznicki J, Wojda U: Calmyrin1 binds to SCG10 protein (stathmin2) to modulate neurite outgrowth. Biochim Biophys Acta 2011;1813:1025-1037.

73 Whitehouse C, Chambers J, Howe K, Cobourne M, Sharpe P, Solomon E: NBR1 interacts with fasciculation and elongation protein zeta-1 (FEZ1) and calcium and integrin binding protein (CIB) and shows developmentally restricted expression in the neural tube. Eur J Biochem 2002;269:538-545.

74 Wang S, Sun Z, Zhang X, Li Z, Wu M, Zhao W, Wang H, Chen T, Yan H, Zhu J: Wnt1 positively regulates CD36 expression via TCF4 and PPAR-gamma in macrophages. Cell Physiol Biochem 2015;35:1289-1302.

75 Hollenbach AD, McPherson CJ, Lagutina I, Grosveld G: The EF-hand calcium-binding protein calmyrin inhibits the transcriptional and DNA-binding activity of Pax3. Biochim Biophys Acta 2002;1574:321-328.

-76 Sun W, Guan Q Wen J, Zhang Q, Yang W, Zhang B, Cui W, Zou Z, Yu Y: Calcium- and integrin-binding protein-1 is down-regulated in the sperm of patients with oligoasthenozoospermia : CIB1 expression in patients with oligoasthenozoospermia. J Assist Reprod Genet 2014;31:541-547.

-77 Godinho-Santos A, Hance AJ, Gonçalves J, Mammano F: CIB1 and CIB2 are HIV-1 helper factors involved in viral entry. Sci Rep 2016;6:30927.

78 Bandyopadhyay C, Valiya-Veettil M, Dutta D, Chakraborty S, Chandran B: CIB1 synergizes with EphrinA2 to regulate Kaposi's sarcoma-associated herpesvirus macropinocytic entry in human microvascular dermal endothelial cells. PLoS Pathog 2014;10:e1003941.

79 Zhao F, Zhang S, Chen L, Wu Y, Qin J, Shao Y, Wang X, Chen Y: Calcium- and integrin-binding protein-1 and calcineurin are upregulated in the right atrial myocardium of patients with atrial fibrillation. Europace 2012;14:1726-1733.

80 Weljie AM, Yamniuk AP, Yoshino H, Izumi Y, Vogel HJ: Protein conformational changes studied by diffusion NMR spectroscopy: application to helix-loop-helix calcium binding proteins. Protein Sci 2003;12:228-236. 